\title{
FORTALECIMENTO DO MANEJO FLORESTAL COMUNITÁRIO EM ASSENTAMENTO RURAL NA AMAZÔNIA OCIDENTAL, RONDÔNIA, BRASIL
}

\author{
Michelliny Bentes-Gama1 ${ }^{1}$, Vânia Beatriz Vasconcellos de Oliveira², \\ Abadio Hermes Vieira ${ }^{3}$, Marilia Locatelli ${ }^{4}$, Vanda Gorete de Souza Rodrigues ${ }^{5}$, \\ Iraque de Moura Medeiros ${ }^{6}$ e Eugênio Pacelli Martins ${ }^{7}$
}

\section{RESUMO}

O assentamento rural Nilson Campos, um dos mais recentes do Estado de Rondônia, localizado no Distrito de Jacy Paraná, a 90 km da capital do Estado, Porto Velho, pode ser considerado um retrato do acelerado processo de ocupação humana na região, caracterizado pelas mudanças na paisagem e no padrão de uso da terra, que tem por base uma agricultura regional continuamente apoiada em práticas de derruba e queima, consideradas mais acessíveis em termos econômicos, porém, causadoras de grandes perdas do capital natural.

Preocupada com essas questões, a Embrapa Rondônia vem conduzindo, desde julho de 2005, o projeto: Organização comunitária em apoio ao manejo florestal em assentamento rural - Jacy Paraná - Rondônia, cujo objetivo central é preparar produtores familiares, assentados de programas da reforma agrária, para implementar o manejo florestal comunitário mediante um programa sócio-educativo que inclui quatro etapas operacionais: sensibilização, capacitação, planejamento e difusão. A partir da metodologia proposta, que inclui a participação dos produtores em grupos de estudo mediante oficinas temáticas com o uso de música como ferramenta de base para a discussão e reflexão sobre a temática ambiental, o fortalecimento do aprendizado sobre a importância, as técnicas, e o esclarecimento sobre os desafios e oportunidades da adoção do manejo florestal têm sido trabalhadas.

São apresentados os principais avanços conseguidos até o momento com a formação de um grupo comunitário de estudo (GCE) local sobre manejo florestal comunitário, a realização de uma oficina de trabalho sobre os cenários futuros plausíveis com o manejo florestal no assentamento, e curso introdutório sobre manejo florestal sustentável, englobando a legislação florestal, e a importância e função de recursos madeireiros e não-madeireiros para a melhoria de suas estratégias de vida.

1 Eng. Florestal, Embrapa Rondônia, Brasil, mbgama@cpafro.embrapa.br

2 Comunicóloga, Coordenadora do Projeto, Embrapa Rondônia, Brasil

3 Eng. Florestal, Embrapa Rondônia, Brasil

4 Eng. Florestal, Embrapa Rondônia, Brasil

5 Eng. Agrônoma, Embrapa Rondônia, Brasil

6 Geógrafo, Embrapa Rondônia, Brasil

7 Eng. Florestal, Secretaria Estadual de Desenvolvimento Ambiental, Rondônia, Brasil 


\begin{abstract}
Nilson Campos rural settlement, one of the most recent in the Sate of Rondônia, located at Jacy Paraná County, $90 \mathrm{~km}$ far from the capital of the State, Porto Velho, can be considered a picture of the accelerated process of human occupation in the region, characterized by landscape and land use pattern changes, which is based on a regional agriculture continuously carried out by slash and burn practices, more economically accessible, though being a great cause of the natural capital loss.

Concerned about this, Embrapa Rondônia has been carrying out, since July 2005, the project: Community organization helping the forest management in rural settlement - Jacy Paraná - Rondônia, which main objective is to prepare family farmers, settled from agrarian reform, for implementing the community forest management through a participatory socio-educative program which includes four operational steps: awareness and engagement, capacitating, planning and diffusion. From the proposed methodology, that includes the farmers participating in groups of study through thematic workshops with the use of music as a base tool for stimulating the discussion an reflection on the environmental theme, the strengthening of learning about the importance, techniques and the challenges and opportunities by the adopting of the forest management have been worked.

It is showed the main outputs until this moment with the formation of a local Community Study Group (CEG) about forest management, involving the participants of the settlement, the held of a workshop on future scenarios for forest management, and a basic course on sustainable forest management, involving environmental laws, and the importance and functions of wood and non wood forest products for improving livelihoods.
\end{abstract}




\section{INTRODUÇÃO}

As comunidades rurais da Amazônia ainda precisam de grande atenção e apoio para conseguir utilizar seus recursos naturais de modo a obter efetivas melhorias sociais, econômicas e ambientais. No Estado de Rondônia, Leste da Amazônia, cerca de $98 \%$ da produção agrícola vêm de áreas de pequenos produtores que ainda apresentam extensos maciços florestais, os quais vêm sendo continuamente substituídos por lavouras de baixa produtividade, ou ainda cultivos perenes e semi-perenes estabelecidos sem maior apoio técnico, prevalecendo as práticas não sustentáveis de derruba e queima que transformam a paisagem e condicionam o uso dos solos no tempo e no espaço.

A história de conversão de uso da terra no Estado está fortemente relacionada à perda da vegetação natural e se inicia com a construção da BR-364 desde a década de 70, a principal rodovia que liga o Estado às demais regiões do Brasil; além desse marco, diversos projetos nacionais de colonização que foram criados para promover o desenvolvimento regional, associados ao período da intensa exploração mineral, ajudaram a acelerar a ocupação de terras na região.

Iniciativas para a promoção do uso sustentável da biodiversidade local e do controle da expansão desordenada das fronteiras de exploração madeireira e agrícola em Rondônia têm sido iniciadas na região. Estudos recentes (Projeto Úmidas, 2002) apontam para a necessidade do empenho dos setores envolvidos na atividade florestal quanto à disseminação da ferramenta manejo florestal, e/ou silvicultura, para proporcionar o retorno sócio-econômico adequado da atividade, tendo em vista as limitadas possibilidades de sustentação do extrativismo madeireiro desordenado que vem sendo praticado no Estado.

A importância do manejo florestal pode ser destacada mediante os seguintes benefícios: a) redução das taxas de desmatamento; b) geração de postos de trabalho; c) redução das taxas de emigração rural; d) diversificação e elevação da renda no meio rural; e) alcance de mercados exigentes (referindo-se à aceitação de produtos florestais certificados com "selo verde"); f) manutenção dos serviços ambientais da floresta (equilíbrio climático e hídrico, conservação da biodiversidade e proteção ao solo); e g) legitimação da indústria de base florestal (Araújo e Oliveira, 1996).

\section{OBJETIVOS}

Desenvolver programa sócio-educativo participativo visando preparar produtores familiares, assentados da reforma agrária, para implementar o manejo florestal comunitário.

Fortalecer o aprendizado dos produtores sobre a importância, técnicas e aspectos legais do manejo florestal.

Estimular a participação dos produtores em discussões e tomadas de decisão para o manejo florestal no Assentamento Nilson Campos. 


\section{ANTECEDENTES GERAIS}

Nilson Campos é um dos recentes assentamentos criados no Estado desde outubro de 2000 pelo Instituto Nacional de Colonização e Reforma Agrária (INCRA), que cadastrou e assentou 126 famílias no local.

A população em potencial do assentamento nessa época estava estimada em torno de 504 pessoas, com uma média do grupo familiar de quatro membros por família.

Em novembro de 2001 a Embrapa Rondônia coordenou a elaboração do Plano de Desenvolvimento Sustentável do Assentamento (PDSA) Nilson Campos. Naquele momento, realizou-se entrevistas com 45 assentados. Do total, verificou-se que $27 \%$ não participavam de nenhuma organização, apesar de já haver duas associações de produtores no local; os produtores raramente participavam de cooperativas e sindicato de trabalhadores rurais. A atividade extrativista era incipiente (Tabela 1) e apenas $38 \%$ declararam praticar alguma atividade relacionada à coleta de frutos, extração de óleos e madeira (Oliveira, 2004).

\section{Tabela 1}

PRINCIPAIS USOS DA TERRA NO ASSENTAMENTO NILSON CAMPOS JACY PARANÁ, PORTO VELHO, RONDÔNIA EM 2001

\begin{tabular}{|l|l|l|}
\hline$\#$ & Uso & $\%$ \\
\hline \multicolumn{2}{|l|}{ Área total: 12.100 ha } & 70 \\
\hline 1. & Floresta nativa & 11 \\
\hline 2. & Pastagem & 13 \\
\hline 3. & Cultivos anuais e perenes & 6 \\
\hline 4. & Capoeira & 100 \\
\hline
\end{tabular}

(Fonte: Oliveira, 2004)

As instituições diretamente envolvidas com o assentamento são: Instituto Nacional de Reforma e Colonização Agrária - INCRA, Associação de Assistência Técnica e Extensão Rural do Estado de Rondônia - EMATER, Secretaria Municipal de Educação - SEMED, e associações de produtores, sobretudo a Associação dos Produtores Rurais de Jacy Paraná - ARJAP.

A origem da proposta de fortalecimento do manejo florestal comunitário no assentamento foi uma das demandas identificadas no PDSA e em outras tentativas de projetos de pesquisa e desenvolvimento para a área (Oliveira et al., 2003) na qual destacou-se o interesse dos produtores pela utilização de recursos madeiráveis e não-madeiráveis /enriquecimento florestal como alternativa de geração de renda. Foi levado em conta também a estratégia governamental para a preservação das florestas nacionais, e a política de promoção do desenvolvimento sustentável do Ministério do Meio Ambiente - MMA e do Ministério do Desenvolvimento Agrário - MDA, cujas políticas baseiam-se na participação comunitária.

A proposta da Embrapa Rondônia foi aprovada em 2004 no componente Iniciativas Promissoras do Projeto de Apoio ao Manejo Florestal Sustentável na Amazônia - ProManejo, 
cujo objetivo é gerar exemplos práticos de sistemas de manejo florestal, a partir de experiências piloto, que contribuam para o aprendizado dos diversos segmentos envolvidos com a questão florestal. O Promanejo foi criado no âmbito do Programa Piloto de Proteção das Florestas Tropicais (PPG-7) e é executado pelo Instituto Brasileiro dos Recursos Naturais Renováveis IBAMA e MMA.

\section{MATERIAL E MÉTODO}

\section{Área de Estudo}

O Estado de Rondônia apresenta área de 238.512,80 km² e está localizado na Amazônia Ocidental ( $7^{\circ} 58^{\prime}$ e $13^{\circ} 43^{\prime}$ S e 59 50' e 66 48' W). Apresenta oito tipos principais de vegetação, sendo a Floresta Ombrófila Aberta o tipo dominante (55\% da área total), seguida pela Floresta Ombrófila Densa (4\%), Cerrado (5\%), entre outras tipologias florestais (Fernandes e Guimarães, 2001).

\section{Assentamento Nilson Campos}

O assentamento Nilson Campos está localizado ao Norte do Estado de Rondônia, no distrito de Jacy Paraná, a 90 km da capital, Porto Velho. O acesso ao assentamento se dá, pelas Linhas 101 e 105 que estão, respectivamente, a 11 e 15 km de Jacy Paraná.

A área está inserida na Subzona 1.2 do Zoneamento Sócio-econômico e Ecológico de Rondônia, na qual predominam a cobertura florestal natural, em processo acelerado de ocupação humana, com conversão da floresta, aptidão agrícola predominantemente regular, vulnerabilidade natural à erosão predominantemente de baixa a média e para a qual se recomenda a regularização fundiária, mas com controle da exploração florestal e do desmatamento.

A área do assentamento é de 12.100 há, dividida em 195 lotes distribuídos em quatro glebas, sendo que $76 \%$ desses lotes são de 50 hectares. A tipologia vegetal predominante é a Floresta Ombrófila Aberta de Terras Baixas, caracterizada por árvores de grande porte.

Entre as espécies madeireiras mais freqüentes estão a castanha do brasil (Bertholletia excelsa), angelim (Hymenolobium sp.), faveira (Parkia sp.), acariquara (Minquartia guianensis), cedro rosa (Cedrella odorata) e cedrinho (Erisma sp.), além de outras espécies de menor valor comercial como a caixeta (Jacaranda sp.) e o marupá (Simarouba amara), palmeiras como o babaçu (Orbignya phalerata) e o tucumã (Astrocaryum aculeatum), e cipós como o titica (Heteropsis flexuosa) e o ambé (Philodendron sp.) (Oliveira, 2004).

\section{Metodología}

A metodologia do projeto utiliza um programa sócio-educativo que inclui quatro etapas operacionais: sensibilização, capacitação, planejamento e difusão (Oliveira, 2004; Oliveira et al, 2006): 
Etapa 1 - Sensibilização: nessa fase ocorre a sensibilização dos produtores sobre a importância do uso racional dos recursos florestais e o estímulo à formação de um grupo de discussão que tenha interesse na implementação do manejo florestal comunitário. São utilizadas dinâmicas de sensibilização, realizadas em oficinas temáticas que funcionam como um espaço para o exercício do "diálogo dos saberes" (Freire, 1977), a construção coletiva de conhecimento, envolvendo o saber local e o saber técnico para a resolução dos conflitos.

Etapa 2 - Capacitação: aqui se trabalha com o grupo de estudo constituído na etapa de sensibilização, propondo diferentes temas a serem debatidos participativamente envolvendo produtores e técnicos. A discussão sobre o manejo florestal comunitário é conduzida como um "tema gerador" em uma unidade de educação agroambiental (UEA), um fórum de debate comunitário (Hammes, 2002), que visa construir em conjunto o conhecimento necessário para compreender a situação e tentar buscar uma resolução de apoio coletivo. Nesse momento também são desenvolvidas atividades de capacitação (cursos e visitas técnicas) preparatórias à etapa seguinte.

Etapa 3 - Planejamento: o trabalho nessa fase é o planejamento da modalidade de manejo a ser implementada no local de estudo, nesse caso, priorizando-se o manejo florestal de pequena escala, de modo a conciliar os objetivos de conservação e desenvolvimento sustentável com os objetivos dos produtores.

Etapa 4 - Difusão: com base nas etapas anteriores, essa funciona como espaço de produção, organização e disseminação das informações transmitidas e geradas de modo participativo, por meio de eventos, publicações e divulgação na mídia impressa e eletrônica, com vistas a viabilizar o acesso à informação a outros grupos interessados em empreender iniciativas de manejo florestal comunitário.

Durante as oficinas, foram utilizadas, como apoio à discussão e reflexão sobre a gestão e uso dos recursos florestais, músicas do repertório popular brasileiro, preferencialmente de artista regional, ou local, cuja letra abordasse questões relacionadas ao tema em discussão nas reuniões com o grupo de estudo.

\section{RESULTADOS E DISCUSSÃO}

\section{Formação do Grupo Comunitário de Estudo (GCE)}

Mediante a realização de oficinas educativas na Etapa I - Sensibilização houve a constituição de um Grupo Comunitário de Estudo (GCE), formado por 12 comunitários e seis técnicos, entre pesquisadores da Embrapa Rondônia e técnicos de instituições parceiras.

A música "Saga da Amazônia" (Xangai - Cantoria 2, 1994) foi uma das ferramentas que permitiu trabalhar a sensibilização quanto à urgência em se reformular o modelo predador de exploração florestal no assentamento (Oliveira et al., 2006). 


\section{Oficina Cenários Futuros Plausíveis para o Manejo Florestal no Assentamento Nilson Campos}

As técnicas de construção de Cenários para a prospecção do futuro não são recentes e passaram a ser formalizadas no início dos anos 50 . Atualmente, os cenários futuros plausíveis tem sido importantes ferramentas adotadas para o planejamento regional, em que pese a sustentabilidade das ações.

Considerando que ao se elaborar qualquer projeto, plano de desenvolvimento ou gerenciamento, que tenha como base os princípios da sustentabilidade, é necessário o atendimento às questões relativas à viabilidade financeira, ecológica, social e tecnológica, torna-se imprescindível que as ações previstas estejam integradas.

A construção de cenários futuros plausíveis permite a integração desses componentes, introduzindo idéias de pensamento sistêmico e de dinâmica de sistemas (mesmo que nem sempre formalizados) na percepção da evolução do presente para o futuro.

A utilização desse exercício permitiu auxiliar os participantes do projeto, bem como as instituições parceiras, na construção de cenários possíveis futuros, considerando os aspectos técnicos, sociais e políticos interligados à utilização dos recursos florestais pelos produtores do assentamento rural Nilson Campos. (Tabela 2).

Para isso realizou-se uma oficina de trabalho durante o primeiro Encontro sobre Manejo Florestal Comunitário em Assentamento Rural - EMFCAR, de 26 a 28 de julho de 2005, em Porto Velho, Rondônia.

A música regional "Pérola Azulada" (Zé Miguel - Acústico, 2001) foi utilizada na abertura do encontro para a motivação do público, tendo em vista a intenção do autor em fazer um tributo ao planeta Terra, conclamando o respeito à natureza (Oliveira et al., 2006).

Tabela 2

PARTICIPAÇÃO POR GÊNERO E PÚBLICO TOTAL DO PRIMEIRO ENCONTRO SOBRE MANEJO FLORESTAL COMUNITÁRIO EM ASSENTAMENTO RURAL - EMFCAR, 26 A 28/07II05, PORTO VELHO, RONDÔNIA

\begin{tabular}{|l|c|c|c|}
\hline \multirow{2}{*}{ Publico } & \multicolumn{3}{|c|}{ Participantes $\left(\mathrm{n}^{\circ}\right)$} \\
\cline { 2 - 4 } & $\mathbf{2 6 / 0 7 / 2 0 0 5}$ & $\mathbf{2 7 / 0 7 / 2 0 0 5}$ & $\mathbf{2 8 / 0 7 / 2 0 0 5}$ \\
\hline Homens & 22 & 15 & 19 \\
\hline Mulheres & 12 & 14 & 31 \\
\hline Total & 34 & 29 & 31 \\
\hline
\end{tabular}


A construção de cenários futuros plausíveis para o assentamento Nilson Campos, envolvendo representantes dos setores ligados à atividade florestal no Estado, permitiu uma ampla discussão técnica e política para o estabelecimento de futuras ações e deliberações necessárias ao estabelecimento do manejo florestal comunitário no local.

Como principais resultados, observou-se que os temas centrais das expectativas sobre o MFC, para os assentados, estavam relacionadas à possibilidade de ampliar o conhecimento sobre o tema e as técnicas do manejo a partir das informações que estariam sendo oferecidas pela programação do evento e pela oficina; enquanto para os parceiros institucionais houve destaque sobre a necessidade de apoio do poder público e recursos financeiros para a execução do manejo florestal.

As principais incertezas para os assentados estavam relacionadas à assistência técnica e financeira, além das preocupações com o cumprimento das exigências burocráticas relacionadas a planos de manejo, para os parceiros institucionais, a organização comunitária teve destaque, sendo um dos quesitos essenciais para o sucesso da atividade, devido à falta de experiência da comunidade com o tema (Tabela 3). 
Tabela 3

EXPECTATIVAS E INCERTEZAS DO PÚBLICO PARTICIPANTE DO PRIMEIRO

ENCONTRO SOBRE MANEJO FLORESTAL COMUNITÁRIO EM ASSENTAMENTO RURAL, 26 A 28/07II05, PORTO VELHO, RONDÔNIA

\begin{tabular}{|c|c|c|}
\hline Participantes & Expectativas & Incertezas \\
\hline \multirow[t]{6}{*}{ Assentamento } & $\begin{array}{l}\text { Organização comunitária para } \\
\text { melhoria da qualidade de vida. }\end{array}$ & Interesse pelas atividades do MFC. \\
\hline & $\begin{array}{l}\text { Conservação ambiental e geração } \\
\text { de renda. }\end{array}$ & $\begin{array}{l}\text { Política publica favorável para a } \\
\text { continuidade da atividade florestal. }\end{array}$ \\
\hline & $\begin{array}{l}\text { Conhecimento do potencial dos } \\
\text { recursos naturais da comunidade. }\end{array}$ & $\begin{array}{l}\text { Assistência técnica e financeira } \\
\text { para a continuidade do projeto. }\end{array}$ \\
\hline & $\begin{array}{l}\text { Acompanhamento da cadeia } \\
\text { produtiva por parte das instituições } \\
\text { envolvidas no projeto. }\end{array}$ & $\begin{array}{l}\text { Interferência no direito de } \\
\text { propriedade do produtor. }\end{array}$ \\
\hline & $\begin{array}{l}\text { Execução do plano de manejo pelos } \\
\text { próprios assentados. }\end{array}$ & $\begin{array}{l}\text { Burocracia dos órgãos ambientais } \\
\text { e a falta de recursos para a } \\
\text { continuidade dos trabalhos. }\end{array}$ \\
\hline & $\begin{array}{l}\text { Recursos para reflorestamento da } \\
\text { área para manter a floresta }\end{array}$ & \\
\hline \multirow[t]{7}{*}{ Parceiros institucionais } & $\begin{array}{l}\text { Conscientização e sensibilização } \\
\text { das instituições governamentais } \\
\text { para que assumam seu papel } \\
\text { perante o meio rural. }\end{array}$ & $\begin{array}{l}\text { Desânimo da comunidade para a } \\
\text { conquista de seus direitos. }\end{array}$ \\
\hline & $\begin{array}{l}\text { Execução do manejo seja feita de } \\
\text { acordo com as instruções do plano } \\
\text { de manejo. }\end{array}$ & Falta de articulação das parcerias. \\
\hline & $\begin{array}{l}\text { Apoio do poder público para o } \\
\text { desenvolvimento do assentamento. }\end{array}$ & $\begin{array}{l}\text { Organização e consciência dos } \\
\text { diversos fatores técnicos inerentes } \\
\text { ao manejo comunitário. }\end{array}$ \\
\hline & $\begin{array}{l}\text { Existência de recursos financeiros } \\
\text { para a execução do plano de } \\
\text { manejo. }\end{array}$ & $\begin{array}{l}\text { Qual o nível de apoio do poder } \\
\text { público pelo manejo florestal } \\
\text { comunitário }\end{array}$ \\
\hline & $\begin{array}{l}\text { Maior compreensão da } \\
\text { complexidade do MFC. }\end{array}$ & $\begin{array}{l}\text { Conhecimento do estoque de } \\
\text { madeira }\end{array}$ \\
\hline & Aprovação do plano de manejo. & \\
\hline & $\begin{array}{l}\text { Que a iniciativa de organização } \\
\text { comunitária sirva como opção } \\
\text { de desenvolvimento p/ áreas de } \\
\text { assentamento }\end{array}$ & $\begin{array}{l}\text { Qual o foco do plano de manejo? } \\
\text { Uso múltiplo ou somente madeira? }\end{array}$ \\
\hline
\end{tabular}




\section{Construindo Cenários Futuros}

Devido ao número de participantes presentes, optou-se pela formação de dois grupos. Os grupos foram divididos a partir da representação de cada instituição parceira, entre outros convidados presentes, além dos representantes dos assentamentos Nilson Campos e Margarida Alves. No Grupo 1 reconstituiu-se o histórico do assentamento de 1987 a 2004; trabalhou-se os pontos focais com perguntas orientadas a solução de principais problemas como a utilização dos recursos naturais do local, políticas públicas; organização comunitária; capacitação e comercialização.

Em seguida o grupo trabalhou os cenários para o Manejo Florestal Comunitário (MFC), em que foram identificados dois interesses entre os participantes: o manejo para a produção de madeira e o manejo para produtos florestais não madeireiros, associado à produção agrícola, consorciada ou não, para isso considerou-se as premissas e as necessidade para se alcançar as metas do manejo florestal em cada cenário (Tabela 4).

\section{Tabela 4}

COMPARAÇÃO ENTRE OS CENÁRIOS FUTUROS PLAUSÍVEIS PARA MANEJO FLORESTAL NO ASSENTAMENTO NILSON CAMPOS PROPOSTOS PELO GRUPO 1 DURANTE O I EMFCAR, PORTO VELHO, RONDÔNIA

\begin{tabular}{|c|c|c|}
\hline Pontos & Cenário 1 & Cenário 2 \\
\hline Geração de renda & $\begin{array}{l}\text { Menor renda em curto prazo, } \\
\text { inicialmente, com perspectiva de } \\
\text { aumento ao longo dos anos. }\end{array}$ & $\begin{array}{l}\text { - Necessidade estabelecimento de } \\
\text { plantações; } \\
\text { - Maior renda imediata, porém, com } \\
\text { diminuição em longo prazo. }\end{array}$ \\
\hline Situação Fundiária & Pendência parcial & $\begin{array}{l}\text { Livre (desde que respeitada a lei } \\
\text { florestal estadual e nacional) }\end{array}$ \\
\hline $\begin{array}{l}\text { Sustentabilidade da } \\
\text { produção }\end{array}$ & $\begin{array}{l}\text { Maior número de espécies de madeira } \\
\text { comercia }\end{array}$ & $\begin{array}{l}\text { Menor número de espécies de } \\
\text { madeira comercia }\end{array}$ \\
\hline $\begin{array}{l}\text { Domínio da } \\
\text { tecnologia }\end{array}$ & $\begin{array}{l}\text { Trabalho mais complexo (exploração } \\
\text { florestal) }\end{array}$ & $\begin{array}{l}\text { Trabalho menos complexo (domínio } \\
\text { do cultivo agrícola) }\end{array}$ \\
\hline $\begin{array}{l}\text { Qualidade de vida } \\
\text { (abrangência) }\end{array}$ & Menor (para poucos) & $\begin{array}{l}\text { Maior (para um maior número de } \\
\text { pessoas) }\end{array}$ \\
\hline Mercado & Mais acessível para a madeira & $\begin{array}{l}\text { Menos acessível para produtos } \\
\text { agrícolas }\end{array}$ \\
\hline
\end{tabular}

O Grupo 2 iniciou a construção de cenários futuros plausíveis até 2020, trabalhando as expectativas e incertezas anteriormente identificadas sobre o manejo florestal comunitário: organização comunitária, preservação da floresta, conhecimento do potencial de recursos florestais, acompanhamento da cadeia produtiva, capacitação dos assentados, recursos para financiamento, apresentando respostas para cada um desses problemas, ente os quais destacaram-se: a divisão de responsabilidades no assentamento; a necessidade uma parceria efetiva das instituições envolvidas com o manejo florestal; a necessidade de capacitação 
em tecnologias de aplicação prática para a condução de um projeto de manejo florestal; e a necessidade de existência de linhas de crédito voltadas ao manejo florestal além de necessidade de investimentos em infra-estrutura no assentamento.

A partir das discussões sobre a potencialidade, limitações e condicionantes os cenários foram projetados (Tabela 5).

Tabela 5

CENÁRIO FUTURO PLAUSÍVEL PARA O MANEJO FLORESTAL NO ASSENTAMENTO NILSON CAMPOS PROPOSTO PELO GRUPO 2, DURANTE O I EMFCAR, PORTO VELHO, RONDÔNIA

\begin{tabular}{|c|c|c|c|c|}
\hline $\begin{array}{r}\text { Cenário atual } \\
1987 \\
\end{array}$ & 1989 & 1998 & 2002 até hoje & \\
\hline $\begin{array}{l}\text { - Mata virgem } \\
\text { - Chegada dos } \\
\text { assentados } \\
\text { - Sem infra-estrutura e } \\
\text { plano de } \\
\text { desenvolvimento } \\
\text { (12 mil hectares) }\end{array}$ & $\begin{array}{l}\text { Exploração de madeira + } \\
\text { pecuária com financiamento } \\
\text { + roça de subsistência } \\
\text { (milho, arroz) } \\
\text { - Escola até a } 4^{\mathrm{a}} \text { série } \\
\text { - Transporte precário }\end{array}$ & $\begin{array}{l}\text { - Abertura de estrada } \\
\text { precária } \\
\text { - Exploraçāo } \\
\text { predatória }\end{array}$ & - Linha de crédito & \\
\hline $\begin{array}{c}\text { Cenário futuro } \\
2005\end{array}$ & 2006 & 2007 & 2010 & 2020 \\
\hline $\begin{array}{l}\text { - Fortalecimento } \\
\text { organizacional dos } \\
\text { assentados } \\
\text { (atualmente } 11 \text { sócios } \\
\text { envolvidos com o } \\
\text { manejo florestal, o } \\
\text { objetivo é aumentar } \\
\text { para } 40 \text { ou mais) } \\
\text { - Atualmente } 126 \\
\text { familias } \\
\text { - Falta divisaão de } \\
\text { responsabilidades } \\
\text { entre os sócios } \\
\text { - A ARJAP iniciou a } \\
\text { efetivaçăo das } \\
\text { parcerias } \\
\text { - Houve melhorias da } \\
\text { estrada e tomada de } \\
\text { providências legais } \\
\text { para a melhoria de } \\
\text { infra-estrutura } \\
\text { - Eletrificaçăo } \\
\text { - Revisão participativa } \\
\text { (inclui plano de } \\
\text { comercializaçăo) } \\
\text { - O I EMFCAR } \\
\text { promoveu a discussão } \\
\text { sobre o plano de } \\
\text { manejo florestal } \\
\text { aprovado e a possivel } \\
\text { reelaboração } \\
\text { direcionado ao manejo } \\
\text { florestal comunitário. } \\
\text { - Inicio de cursos de } \\
\text { capacitação nos temas } \\
\text { relacionados ao } \\
\text { manejo florestal } \\
\text { (Embrapa Rondônia). } \\
\text { - Intercâmbio com } \\
\text { outros projetos de } \\
\text { assentamento }\end{array}$ & $\begin{array}{l}\text { - Inicio da execução do plano } \\
\text { de manejo florestal } \\
\text { comunitário }\end{array}$ & $\begin{array}{l}\text { - Eletrificação } \\
\text { completa do } \\
\text { assentamento } \\
\text { - Cooperativa com } \\
\text { maior número de } \\
\text { cooperados (pelo } \\
\text { menos } 60 \text { ) } \\
\text { - Vicinais e } \\
\text { carreadores prontos } \\
\text { - Situação fundiária } \\
\text { regularizada } \\
\text { - Competências } \\
\text { consolidadas } \\
\text { - Ampliação de } \\
\text { mercado } \\
\text { - Produçăo e } \\
\text { comercializaçăo } \\
\text { crescentes } \\
\text { - Aumento de renda e } \\
\text { melhoria de qualidade } \\
\text { de vida }\end{array}$ & $\begin{array}{l}\text { - Ampliação do } \\
\text { mercado(local, } \\
\text { regional, nacional, } \\
\text { internacional) } \\
\text { - Aperfeiçoamento do } \\
\text { sistema produtivo } \\
\text { (SAFs) } \\
\text { - Consolidação da } \\
\text { cooperativa } \\
\text { - Instalaçăo de } \\
\text { indústrias } \\
\text { processadoras } \\
\text { - Mecanizaçăo + } \\
\text { movelarias e serrarias } \\
\text { - Ganho ambiental }\end{array}$ & $\begin{array}{l}\text { - Nova geração } \\
\text { emergindo, já capacitada } \\
\text { e autônoma com } \\
\text { equilibrio sócio- } \\
\text { econômico e ambiental. }\end{array}$ \\
\hline
\end{tabular}




\section{Capacitação em Manejo Florestal}

Entre os cursos planejados para o fortalecimento do aprendizado sobre a importância, as técnicas, e o esclarecimento sobre os desafios e oportunidades da adoção do manejo florestal, foi promovido em 01/12/2005 o Curso Manejo Florestal Sustentável (Módulo i). O objetivo deste curso foi introduzir a importância e os conceitos básicos sobre o manejo florestal aos participantes do grupo comunitário de estudos sobre manejo florestal, uma das demandas destacadas na oficina de cenários futuros plausíveis. Participaram do curso 10 produtores rurais do assentamento, além de dois extensionistas rurais (Cooperativa Milênio) e dois integrantes da equipe do Projeto da Embrapa Rondônia.

O conteúdo do curso Manejo Florestal Sustentável (Módulo I), foi o seguinte: pela manhã - histórico sobre o manejo florestal; importância da conservação das florestas naturais; crescimento das preocupações ambientais e manejo florestal como a prática ideal para o uso dos recursos florestais; pela tarde - importância do manejo florestal; conceitos usados no manejo florestal; definição de manejo florestal sustentável; importância, finalidade, requisitos.

Houve a integração de três novos produtores no grupo de estudo sobre manejo florestal no assentamento, além dos participantes que já haviam firmado compromisso no início do projeto. Observou-se uma boa aceitação das informações repassadas no curso e a integração do grupo no momento de registrar suas impressões. As principais impressões e opiniões do grupo foram referentes o nível das informações, a necessidade de assistência técnica em manejo florestal, a importância e os benefícios de manter a reserva florestal, além de indicações para o trabalho com artesanato, principalmente o babaçu (Orbygnia phalerata) e sementes de açaí (Euterpe sp.). A revisão desses conceitos na próxima reunião de continuação do curso deverá ser realizada como forma de relembrar e checar o aprendizado do grupo.

Atualmente se encontram no assentamento apenas 180 famílias. Segundo os produtores que permanecem no assentamento, o desestímulo das pessoas vem justamente da falta de apoio ao assentamento (infra-estrutura) e da falta de interesse por parte de algumas pessoas, que querem soluções imediatas, onde algumas até expressam que participariam do Projeto se houvesse algum retorno econômico. A principal conclusão do grupo ao final do curso foi a importância de saber explorar apenas a quantidade necessária de madeira e outros recursos, respeitando-se o tempo de recuperação da floresta.

\section{CONCLUSÕES}

Avaliações a respeito das mudanças ocorridas desde a implementação do projeto no assentamento Nilson Campos ainda estão em andamento, porém, a princípio, pode-se afirmar que a metodologia sócio-educativa que promove a criação de um espaço para estudos em grupo estimula a participação dos produtores envolvidos no processo e facilita a interação com a equipe técnica do projeto.

Entre as ferramentas utilizadas, o exercício dos cenários futuros plausíveis com enfoque no manejo florestal para o assentamento permitiu a geração de informações sobre as expectativas e incertezas da adoção do manejo florestal comunitário pelos moradores do assentamento; indicou o retrato atual das principais dificuldades vivenciadas com relação ao 
uso dos recursos florestais, e permitiu a projeção de cenários viáveis com o manejo florestal no assentamento. Grande parte das demandas indicadas nessa oficina tem sido contemplada nos cursos de capacitação voltados á disseminação de técnicas do manejo florestal, conjugadas com informações sobre a legislação florestal e os benefícios do uso sustentável do s recursos naturais. A utilização da música regional para estimular a discussão e a reflexão sobre a temática ambiental também tem se apresentado como uma ferramenta eficiente para se atingir os objetivos propostos no projeto.

\section{REFERÊNCIAS}

Araújo, H. J. B.; Oliveira, L. C., 1996. Manejo florestal sustentado em áreas de reserva legal de pequenas propriedades rurais do PC. Pedro Peixoto - Acre. Rio Branco: Embrapa-CPAF/AC. 7p. (EMBRAPA-CPAF/AC. Pesquisa em Andamento, 89).

Bartholo Jr., R. S.; Bursztyn, M., 1999. Amazônia sustentável: uma estratégia de desenvolvimento para Rondônia 2020. Porto Velho: PNUD, 246p.

Fernandes, L. C.; Guimarães, S. C (coord.), 2001. Atlas Geoambiental de Rondônia. Porto Velho: SEDAM, 74p. v.2.

Hammes, V. S.., 2002. Atores sociais e unidades de educação (agro)ambiental. In: Hammes, V. S. (Org.). Educação ambiental para o desenvolvimento sustentável. $2^{\mathrm{a}}$ ed. Brasília, v. 2, p. 258-260.

Oliveira, V. B. V.; Locatelli, M.; Leônidas, F. das C.; Pereira, R. G. A.; Medeiros, I. M.; Rosa-Neto, C.; Gonzaga, D. S. O. M.; Holanda-Filho, Z., 2003. Agricultura familiar e plano de desenvolvimento sustentável do assentamento Nilson Campos. Porto Velho: Embrapa CPAF Rondônia, 18p. (Embrapa Rondônia. Documentos, 67).

Oliveira, V. B. V.; Bentes-Gama, M. de M.; Vieira, A,; Rodrigues, V. G. S.; Locatelli, M., 2006. Organização e sensibilização para o manejo florestal comunitário em assentamento rural. In: Encontro da Associação Nacional de Pós-Graduação e Pesquisa em Ambiente e Sociedade ANPPAS, 3., Brasília: ANPPAS,. (GT 7 - Manejo Comunitário de Recursos Naturais).

Oliveira, V. B. V., 2004. Organização Comunitária em Apoio ao Manejo Florestal em Assentamento Rural - Jacy Paraná - Rondônia. Porto Velho: Embrapa Rondônia, 23p. 2004 (Projeto de Desenvolvimento enviado ao Programa Apoio ao Manejo Florestal Sustentável na Amazônia - Promanejo - Edital- Ibama - Ministério do Meio Ambiente; Aprovado em: Outubro/2004, Projeto $n^{\circ}$ 1059).

PROJETO ÚMIDAS, 2002. Uma estratégia de desenvolvimento sustentável para Rondônia: aspectos econômicos. [http://www.rondonia.ro.gov.br/MEM/9/1/dicap1a.htm]. (17/07/2002). 
FORTALECIMENTO DO MANEJO FLORESTAL COMUNITÁRIO EM ASSENTAMENTO RURAL NAAMAZÔNIA OCIDENTAL; RONDÔNIA, BRASIL 